\title{
EXPERIENCIAS DE POLÍTICA MONETARIA EN ECONOMÍAS PEQUEÑAS Y ABIERTAS: CHILE 2012-2016*
}

\author{
Rodrigo Vergara \\ Centro de Estudios Públicos
}

\begin{abstract}
RESUMEN: En esta conferencia, el autor reflexiona sobre los desafíos de la política monetaria en economías pequeñas y abiertas como la chilena. A modo de ilustración, se refiere en particular a la política monetaria que se siguió en Chile durante su mandato como presidente del Banco Central, entre diciembre de 2011 y diciembre de 2016. Tangencialmente, describe también las políticas que siguieron otros países de la región y cómo ellas se asemejan o difieren de la chilena en distintos aspectos.
\end{abstract}

Palabras Clave: política monetaria, banco central, estabilidad financiera, inflación.

\footnotetext{
Rodrigo Vergara. PhD en economía por Harvard University. Profesor del Instituto de Economía de la Pontificia Universidad Católica de Chile. Presidente del Banco Central entre 2011 y 2016. Investigador del Centro de Estudios Públicos. Email: rvergara@cepchile.cl.

* Este artículo corresponde a una versión corregida y extendida del discurso que el autor dio el 21 de abril de 2017, con ocasión de recibir el premio Club Monetario 2016. El autor agradece los comentarios de Sebastián Claro y la valiosa colaboración de Catalina Morales.
} 


\section{MONETARY POLICY IN SMALL OPEN ECONOMIES: CHILE 2012-2016}

ABSTRACT: The author of this lecture reflects on monetary policy challenges in small open economies like Chile. By way of illustration, he refers in particular to the monetary policy followed in Chile during his term as chairman of the Central Bank, between December 2011 and December 2016. He also touches on the policies that were followed by other countries in the region and on the various ways in which they resembled and differed from Chilean policy.

KEYWORDS: monetary policy, central banking, financial stability, inflation.

\section{INTRODUCCIÓN}

E 1 principal objetivo de este artículo es reflexionar sobre política monetaria en economías pequeñas y abiertas como la chilena. Me voy a referir en particular a la política monetaria que se siguió en Chile durante mi mandato como presidente del Banco Central; esto es, en los cinco años que van entre diciembre de 2011 y diciembre de 2016. Pero además voy a referirme, tangencialmente, a las políticas que siguieron otros países de la región y cómo ellas se asemejan o difieren de la chilena en distintos aspectos. Luego de esta breve introducción, en la sección que sigue se entregan antecedentes económicos del periodo. A continuación, en la sección 3, se hace un análisis sobre la política monetaria en Chile, con especial foco en lo sucedido en el período ya mencionado. La sección 4 contiene reflexiones sobre estabilidad financiera, un tema de gran preocupación y ocupación de los bancos centrales alrededor del mundo, que se hizo más visible recientemente debido a la crisis financiera global de 2008-2009. La sección 5 concluye.

\section{ANTECEDENTES}

Chile tiene hace más de 15 años un esquema pleno de metas de inflación. Incluso se podría decir que, desde que posee autonomía (a fines de 1989) hasta el año 2000, el Banco Central tuvo un esquema que en muchos aspectos fue uno de esta naturaleza, en cuanto se fijaron metas para dicha variable. Durante esos años las metas fueron cayendo hasta 
llegar al 3 por ciento actual a principios de la década pasada (gráfico 1). Lo interesante es que siempre dichas metas se fueron cumpliendo. En algunos casos correspondían a un rango y en otros, a un punto, pero siempre se estuvo cerca de ellas. Esto tiene mucho que ver, por cierto, con la credibilidad acumulada por la institución desde entonces. Con todo, se sostiene que el esquema pleno de metas de inflación parte en 2000 , porque previo a ello había algunas condiciones que no se cumplían, entre ellas, quizás la más importante, la no existencia de otros objetivos competitivos. Recordemos que hasta 1999 hubo un tipo de cambio semifijo o de bandas cambiarias, lo que implicaba que había también un objetivo en este ámbito.

Gráfico 1. INFLACIÓN Y METAS DE INFLACIÓN EN CHILE

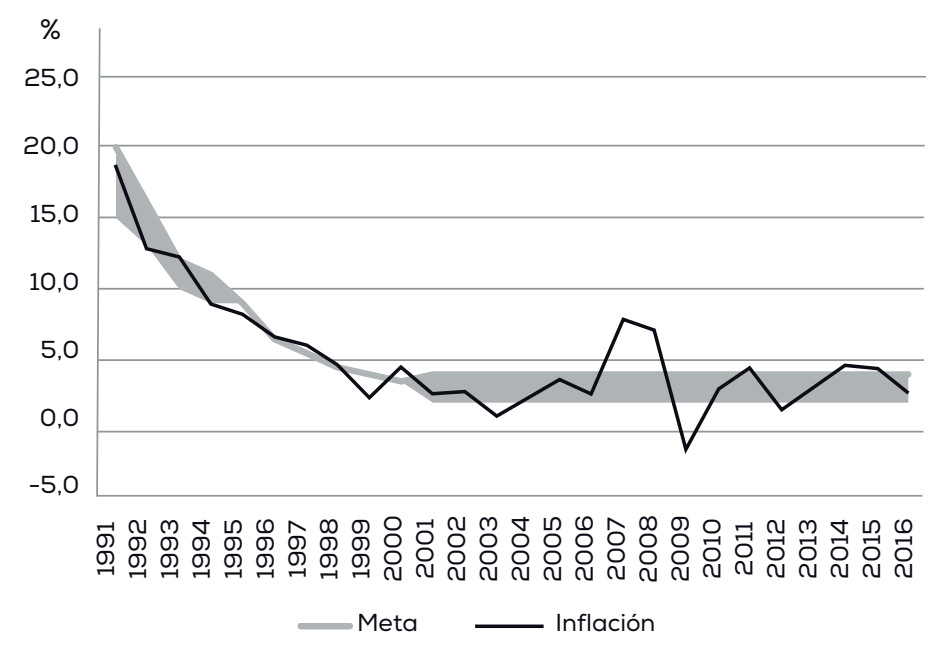

Fuente: Banco Central de Chile.

En el caso de Chile, la meta a partir de 2001 es de 3 por ciento con un rango de tolerancia de 1 por ciento, lo que quiere decir que se espera que la inflación esté la mayor parte del tiempo en dicho rango. Es interesante este punto, porque si bien la inflación promedio en Chile desde 2001 a 2016 ha sido 3,3 por ciento, lo que es muy cercano a la meta del Banco Central, también es cierto que una buena parte del tiempo ha estado fuera de dicho rango. En efecto, el 48 por ciento del tiempo ha sido así (gráfico 1). Los agentes económicos han entendido que los shocks que sufre una economía pequeña y abier- 
ta como la chilena, que además es exportadora de materias primas, conducen a una gran volatilidad de la inflación, y que lo importante es que en promedio esté cerca de la meta. De hecho, hay muchos países que no se ponen rangos tan específicos como lo hacemos nosotros, y, si lo hacen, muchas veces no se ponen límites de tiempo en que la inflación debe acercarse a la meta (recordemos que en el caso de Chile dicho límite es de dos años). Muchos hablan de un objetivo de inflación de, por ejemplo, 2 por ciento, en el "mediano plazo" sin establecer un período específico. Entre ellos están países símbolo de metas de inflación, como Nueva Zelanda, Australia y Suecia (cuadro 1). Ello da mayor flexibilidad a la política, aunque también, debe reconocerse, que podría traducirse en menor credibilidad de la meta. Me parece que es un tema interesante de estudiar y analizar a futuro. ${ }^{1}$

Cuadro 1. HORIZONTES DE META DE INFLACIÓN

\begin{tabular}{ll}
\hline Pais & Plazo meta de inflación \\
\hline Brasil & 1 año \\
Chile & 2 años \\
Colombia & 2 años \\
Australia & "On average over time" \\
Noruega & "Over time" \\
Nueva Zelanda & "On average over the medium term" \\
Suecia & "Over the medium term" \\
Zona Euro & "Over the medium term" \\
USA & "Over the longer run" \\
Perú & En el tiempo \\
México & Mediano plazo \\
\hline
\end{tabular}

Fuente: Banco Central de cada pais.

Quiero detenerme un momento en el tema de la meta y su cumplimiento. Ya vimos que en Chile se ha cumplido, lo que se ha traducido en una gran reputación del Banco Central en esta materia. No ha sido así en todos los países. En el cuadro 2 se observa la meta de inflación y el promedio de inflación efectiva desde que se adoptó dicha meta para

\footnotetext{
${ }^{1}$ Para un análisis conceptual del esquema de metas de inflación en Chile, ver Banco Central (2007).
} 
los países de la Alianza del Pacífico y Brasil. Es evidente que quedamos muy bien parados en dicha comparación. Desde que adoptamos este esquema, en promedio, nuestra inflación ha sido sólo de tres décimas por arriba de la meta. En el país que nos sigue, Colombia, la diferencia es más del doble, de ocho décimas. En los otros países aquí considerados la diferencia supera un punto porcentual (gráfico 2).

Cuadro 2. META DE INFLACIÓN VERSUS INFLACIÓN EFECTIVA

\begin{tabular}{lcccc}
\hline & Meta & Rango & $\begin{array}{c}\text { Año de } \\
\text { implementación }\end{array}$ & $\begin{array}{c}\text { Inflación promedio } \\
\text { del periodo } \\
\text { (a dic. 2016) }\end{array}$ \\
\hline Chile & 3,0 & $2,0-4,0$ & 2001 & 3,3 \\
Perú & 2,0 & $1,0-3,0$ & 2006 & 3,1 \\
Colombia & 3,0 & $2,0-4,0$ & 2010 & 3,8 \\
México & 3,0 & $2,0-4,0$ & 2002 & 4,1 \\
Brasil & 4,5 & $2,5-6,5$ & 2006 & 6,0 \\
\hline
\end{tabular}

Fuente: Banco Central de cada pais y OECD.

Gráfico 2. DIFERENCIA ENTRE LA INFLACIÓN EFECTIVA Y LA META DE INFLACIÓN

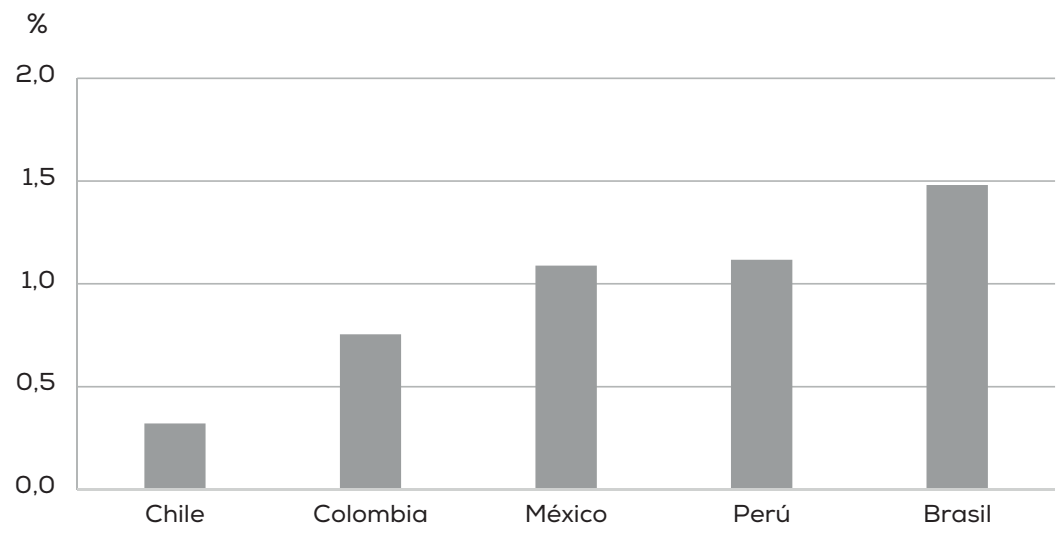

Fuente: Banco Central de cada pais y OECD.

En un esquema de metas de inflación lo clave es la expectativa de inflación del mercado en el horizonte de política, lo que evidentemente está relacionado, entre otras cosas, con la historia de cumplimiento de las metas. Esta expectativa se mide, entre otras fuentes, mediante la Encuesta de Expectativas Económicas que hace el Banco Central. Ya hablamos 
que en algunos casos el horizonte de política puede ser difuso, pero no en el caso de Chile: se ha definido de dos años. ¿Qué significa esto? Que a dos años las expectativas de inflación deben estar en la meta. Si no es así, la política debe modificarse para que las expectativas vuelvan a la meta. Así, por ejemplo, si las expectativas de inflación a dos años superan la meta, entonces se requiere una política monetaria más restrictiva y viceversa. Tal como demuestran los estudios teóricos sobre metas de inflación, en una regla de Taylor (Taylor 1993), más que la inflación actual, lo clave es la inflación proyectada o esperada por el mercado a cierto plazo (Svensson 1997) en relación a la meta de inflación. En otras palabras, se trata de una regla de política que mira al futuro y no al pasado para determinar sus acciones. En la práctica, esto funciona a través de las proyecciones que hace el propio Banco Central con sus modelos. Si al utilizar la tasa de política monetaria (TPM) actual los modelos indican que la inflación estará desviada de la meta en el horizonte de proyección, entonces cabe hacer un cambio de política. Otra forma de ponerlo es que el modelo entrega la trayectoria de la TPM coherente con una inflación de 3 por ciento a dos años. Si dicha trayectoria no es coherente con la actual, entonces cabría modificar la trayectoria esperada para la TPM, lo que probablemente implicará empezar desde ya.

Al referirnos al caso chileno es importante recalcar que durante todo el período que va entre diciembre de 2011 y diciembre de 2016 las expectativas de inflación a dos años estuvieron ancladas en el 3 por ciento. Ello demuestra la credibilidad del instituto emisor. En otras palabras, el mercado apostaba a que el Banco Central haría lo que fuera necesario para cumplir dicha meta. Hacer lo que sea necesario en estos casos es aplicar la dosis adecuada de política monetaria. El gráfico 3 exhibe la proyección de inflación del mercado a dos años. Como se puede ver, en la práctica es una constante de 3 por ciento durante el período. También se ha dibujado la inflación esperada a un año, que por cierto es más volátil, pero que también está cerca del 3 por ciento, con algunos episodios donde la desviación es algo mayor. Es evidente que las expectativas a un año son más volátiles, porque la economía está sujeta a una serie de shocks con efectos de corto plazo. Como muchos de estos shocks son de oferta no tiene mucho sentido compensarlos, al menos totalmente, con política monetaria. Incluso si se tiene la convicción de que el shock de oferta tendrá efectos de segunda vuelta y, luego, sí cabe una reacción de política monetaria, ésta no tendrá todo el efecto desea- 
do en el plazo de un solo año. En otras palabras, sería absurdo pretender estabilizar la inflación a un año en un país como Chile, y creo que, en términos prácticos, en casi en cualquier país del mundo. Volvemos aquí a la pregunta ya planteada: ¿es dos años el plazo adecuado?, ¿sería más razonable movernos a un esquema más flexible, donde se hablara de mediano plazo y no de un plazo específico? Dejo esa pregunta para el análisis y las reflexiones que se puedan hacer a futuro.

Gráfico 3. CHILE: EXPECTATIVAS DE INFLACIÓN

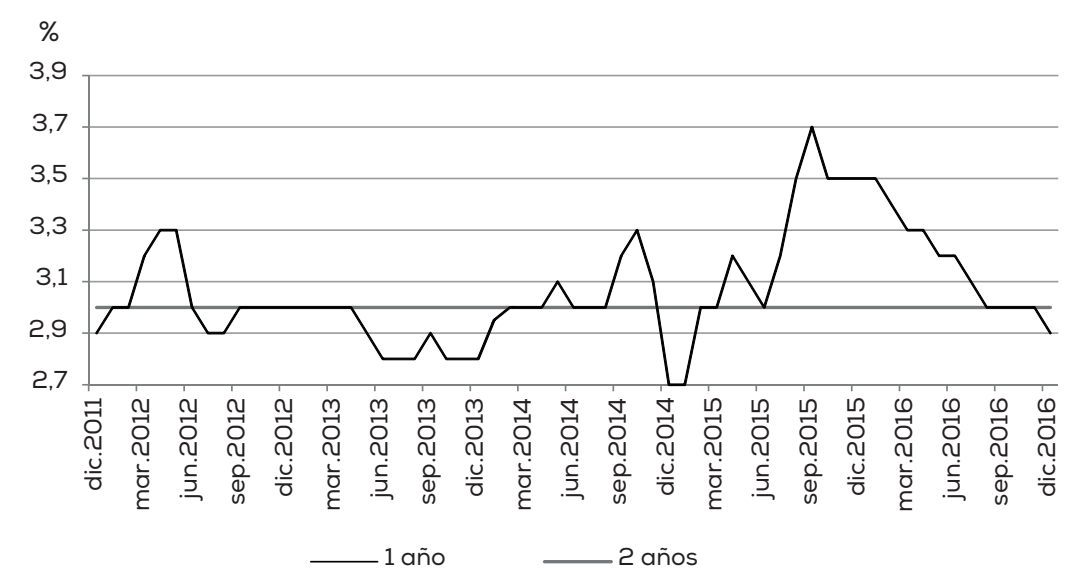

Fuente: Banco Central de Chile, Encuesta de Expectativas Económicas.

Un punto importante que se debe aclarar aquí: que la inflación esperada a dos años sea de 3 por ciento no significa por supuesto que efectivamente la inflación a dos años será 3 por ciento. Obviamente habrá errores de predicción. Lo fundamental es que la predicción sea 3 por ciento y también, cómo no, que a largo plazo se cumpla la meta, porque si no es así se perderá credibilidad en la misma.

Si tomamos un horizonte más largo, como el que se aprecia en el gráfico 4, vemos que hay cuatro períodos con algún desanclaje de expectativas inflacionarias. El primero, al comienzo de la implementación de las metas de inflación plenas en 2001. No me parece particularmente relevante porque se venía de una meta, para el año previo, de 3,5 por ciento y, por lo tanto, es posible que simplemente se esperaba que esa cifra se mantuviera. Rápidamente la expectativa se fue a 3 por ciento. Después, hay dos breves períodos donde las expectativas fueron levemente distintas a la meta: a comienzos de 2004, cuando fueron algo 
menores, y a comienzos de 2011, donde fueron algo mayores. El período más complejo desde que tenemos metas de inflación plenamente vigentes, cuando las expectativas de inflación en Chile se desanclaron claramente, fue en 2008. En ese entonces las expectativas a dos años llegaron casi a un punto porcentual por sobre la meta. Se trata de una diferencia significativa, que además se prolongó por un tiempo relevante (prácticamente un año). Debemos recordar que en esa época la inflación efectiva superó el 7 por ciento por más de un año, e incluso llegó a un peak de 9,9 por ciento.

Gráfico 4. CHILE: EXPECTATIVAS DE INFLACIÓN A DOS AÑOS

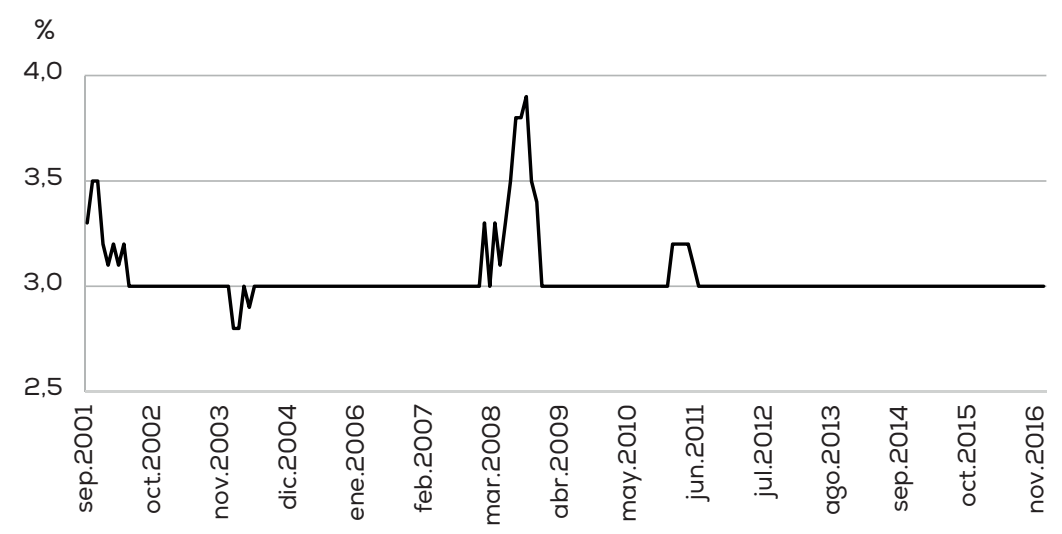

Fuente: Banco Central de Chile, Encuesta de Expectativas Económicas.

Además de la Encuesta de Expectativas Económicas, existen otras mediciones para tomar el pulso del mercado, como la Encuesta de Operadores Financieros, del propio Banco Central, o los precios de mercado. Algunas de estas otras mediciones de expectativas muestran algo más de volatilidad, pero todas son coherentes con expectativas de inflación a dos años ancladas en 3 por ciento. ${ }^{2}$ En general, se puede

${ }^{2}$ La Encuesta de Operadores Financieros, que también realiza el Banco Central desde 2009, pero que se hace sólo a operadores de mercado, se ha desviado en algunas ocasiones, sólo muy marginalmente, de 3 por ciento para la inflación esperada en el segundo año. Concretamente, en el período entre diciembre de 2011 y diciembre de 2016 el máximo promedio mensual es 3,2 y el mínimo, 2,8. La compensación inflacionaria medida por los swaps, por su parte, es más volátil, pero sólo hay un mes en que el promedio de dicha inflación esperada es menor que 2,5 por ciento y sólo otro mes que es mayor a 3,5. En 2008 estuvo, no obstante, nueve meses seguidos por arriba de 3,5 por ciento y llegó incluso a superar el 5 por ciento. 
decir que todas las fuentes de información disponibles coinciden en que el año 2008 fue el período con mayor desanclaje de expectativas de inflación desde que se tiene un esquema de metas de inflación en Chile.

Es necesario hacer aquí un argumento referido a la importancia de la actividad en la política monetaria. Es evidente que desde el punto de vista del bienestar el crecimiento es fundamental, definitivamente más que la inflación si vemos estas dos variables aisladamente. ¿Por qué entonces el Banco Central no tiene un doble objetivo: inflación y crecimiento? En la práctica de la política monetaria, el crecimiento tiene gran relevancia. De hecho, para el logro del objetivo inflacionario la política monetaria busca suavizar el ciclo económico; esto es, hacer menos fuertes las expansiones y menos contractiva la parte baja del ciclo. En un modelo en el que la capacidad ociosa (la conocida brecha del producto) afecta la inflación, el crecimiento es un objetivo intermedio de la política monetaria. En otras palabras, la política monetaria sí considera el crecimiento económico en sus decisiones. La experiencia chilena de 2012-2016 está llena de esos ejemplos, tal como lo veremos más adelante. Más en general, los esquemas de metas de inflación tienen el apellido de "flexible" (Svensson 2009), precisamente para dejar claro que se requiere flexibilidad con el objetivo de hacerse cargo de los temas de crecimiento en el corto plazo. En otras palabras, no sólo se busca suavizar la inflación, sino también el ciclo. Por cierto en un modelo neokeynesiano, como los que usan la gran mayoría de los bancos centrales del mundo, ambas variables están relacionadas.

Dado lo anterior, la pregunta que surge naturalmente es: ¿por qué no incluir el crecimiento o el empleo explícitamente como objetivo? Yo diría que hay dos argumentos, relacionados entre sí. En primer lugar, en el largo plazo, el crecimiento y el empleo no dependen de la política monetaria sino de otros factores; factores reales como la productividad, la inversión o la demografía. La política monetaria tiene poder para suavizar el ciclo, pero no para ir más allá. Por lo tanto, el crecimiento como objetivo explícito podría llevar a una confusión sobre lo que puede y no puede hacer un Banco Central. En segundo lugar, el poner explícitamente una meta de crecimiento o de empleo podría generar mayor presión política sobre el Banco Central para ir más allá de lo que se puede hacer para suavizar el ciclo. ${ }^{3}$

${ }^{3}$ Esto se relaciona con la denominada inconsistencia dinámica en política monetaria (Barro y Gordon 1983). 
Un último tema antes de entrar en más detalle de la experiencia chilena reciente dice relación con la política cambiaria, tema que estará presente en todo el análisis que viene. En Chile, se tiene una política cambiaria de tipo de cambio flexible, pero en la que el Banco Central se reserva el derecho a intervenir si el tipo de cambio se aleja — por un margen significativo y por un período prolongado- de sus niveles de equilibrio de largo plazo. ${ }^{4}$ Las últimas intervenciones fueron en 2008 y 2011, donde se adquirieron montos significativos de reservas en un escenario donde las presiones a la apreciación del peso eran importantes. A partir de fines de 2011 no ha habido intervenciones cambiarias y se ha dejado flotar libremente el tipo de cambio de acuerdo a las fuerzas del mercado. Por cierto que sí hubo presiones importantes para intervenir, en particular durante 2012 y la primera parte de 2013, cuando los sectores exportadores se sentían perjudicados por un tipo de cambio que consideraban bajo. Incluso hubo algunas presiones en el sentido opuesto, cuando el tipo de cambio subió fuertemente en 2013-2015.

\section{ANÁLISIS DE LA POLÍTICA MONETARIA EN CHILE: 2012-2016}

\subsection{Período 2012-2013: alto crecimiento y baja inflación}

Desde el punto de vista de un banquero central no hay mejor escenario posible que aquél en que la inflación es baja (aunque no "tan baja", porque también trae problemas y si se prolonga podría no cumplirse la meta de inflación) $)^{5}$ y el crecimiento es elevado. Esto sucedió en 2012 y 2013. El primer año el crecimiento fue 5,3 por ciento y la inflación, 1,5 por ciento a diciembre. La baja inflación estuvo influenciada por un tipo de cambio nominal que se mantuvo, en lo grueso, estable durante ese año y un tipo de cambio real que entre diciembre de 2011 y diciembre de 2012 cayó 7 por ciento. Durante 2013, el crecimiento cayó a 4 por ciento, con una trayectoria pareja y una desaceleración algo mayor a fines de año. La inflación por su parte se mantuvo bajo la meta de 3 por ciento hasta noviembre, con un mínimo de 0,9 en mayo, subiendo a 3 por ciento en diciembre.

\footnotetext{
${ }^{4}$ Nivel de equilibrio que, por cierto, es muy difícil de determinar. El instituto emisor tiene distintos modelos para estos efectos.

${ }^{5}$ En los últimos años, este caso de inflación muy baja ha estado presente en un buen número de países desarrollados.
} 
Gráfico 5. CHILE: INFLACIÓN (IPC) Y TASA DE POLÍTICA MONETARIA (TPM)
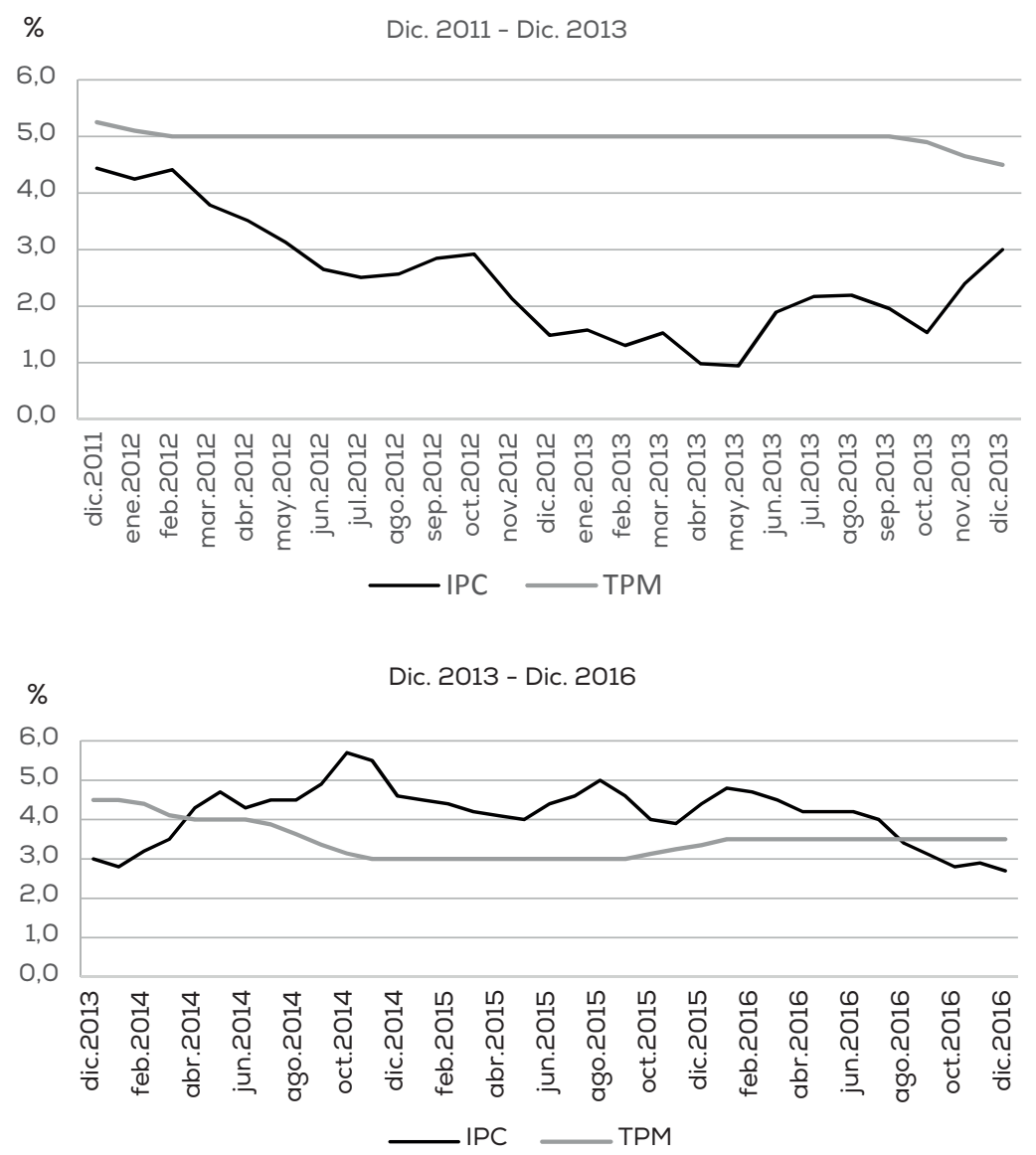

Fuente: Banco Central de Chile.

En el panel superior del gráfico 5 se observa la trayectoria de la inflación y la TPM durante este período. En el inferior se observan ambos índices para el período 2014-2016. Se aprecia que durante 2012, con una inflación baja, la política monetaria se mantuvo con tasas que eran relativamente elevadas, verificándose sólo una disminución de 25 puntos base (de 5,25 a 5 por ciento) en enero de ese año. La razón para mantener la tasa en niveles elevados fue que las altas cifras de crecimiento que venía exhibiendo la economía (en los dos años previos había crecido 6 por ciento promedio anual y en 2012 lo hizo sobre 5; la demanda interna, por su parte, había crecido por arriba de 10 por ciento en promedio entre 2010 y 2012) implicaban un cierre de brechas de ca- 
pacidad que, con una menor tasa de interés, generaría presión sobre los precios e inflaciones mayores a la meta en el horizonte de proyección. Vemos, entonces, como consideraciones con respecto a la suavización del ciclo económico estuvieron presentes en este análisis, lo que ratifica que no es correcto sostener que el crecimiento no es parte del esquema de política monetaria.

De alguna forma, éste es un episodio que demuestra la filosofía de la política monetaria en un esquema de metas de inflación. Más que la inflación del momento, lo relevante es la proyección de esta variable, para lo cual son claves las brechas de capacidad existentes así como las proyectadas. El gráfico 6 muestra la TPM y la actividad. En el panel superior se observa que en 2012 y una buena parte de 2013 la economía sigue con una actividad muy dinámica y la tasa de política se mantiene en 5 por ciento. En el panel inferior (2014-2016) ambas bajan.

En general, el período 2012 y 2013 fue de relativa tranquilidad para la política monetaria: el elevado crecimiento y la inflación controlada conformaban un escenario macroeconómico robusto. A ello se sumaban cuentas fiscales que habían mejorado ostensiblemente en los años recientes y que, en promedio, en esos dos años marcaron un equilibrio.

Había, sí, algunas preocupaciones. Una de ellas era un déficit en cuenta corriente, que llegó a 4 por ciento del PIB en promedio en ambos años. Otra, relacionada con la anterior, fue la apreciación real del tipo de cambio. Tal como se mencionó, el tema cambiario estuvo presente en parte importante del período y hubo voces que pedían la intervención del Banco Central. La apreciación de su consejo fue que no había elementos que justificaran una intervención, que sería costosa y posiblemente tendría poca efectividad. Tampoco se estimó que el tipo de cambio estuviera alejado de sus fundamentos de largo plazo, al menos de forma significativa.

Todo este panorama empezó a cambiar en mayo de 2013, cuando el entonces presidente de la Reserva Federal, Ben Bernanke, hizo el famoso discurso en que habló de una reducción en el ritmo de compra de activos por parte del banco central norteamericano (Bernanke 2013). Este episodio, conocido posteriormente como el "Taper Tantrum", llevó a una fuerte alza de las tasas de interés en Estados Unidos. ${ }^{6}$ Junto con

\footnotetext{
${ }^{6}$ Las tasas de interés de los bonos del Tesoro a diez años subieron en los meses siguientes más de 100 puntos base.
} 
Gráfico 6. CHILE: TASA DE POLÍTICA MONETARIA (TPM) Y ACTIVIDAD (IMACEC)
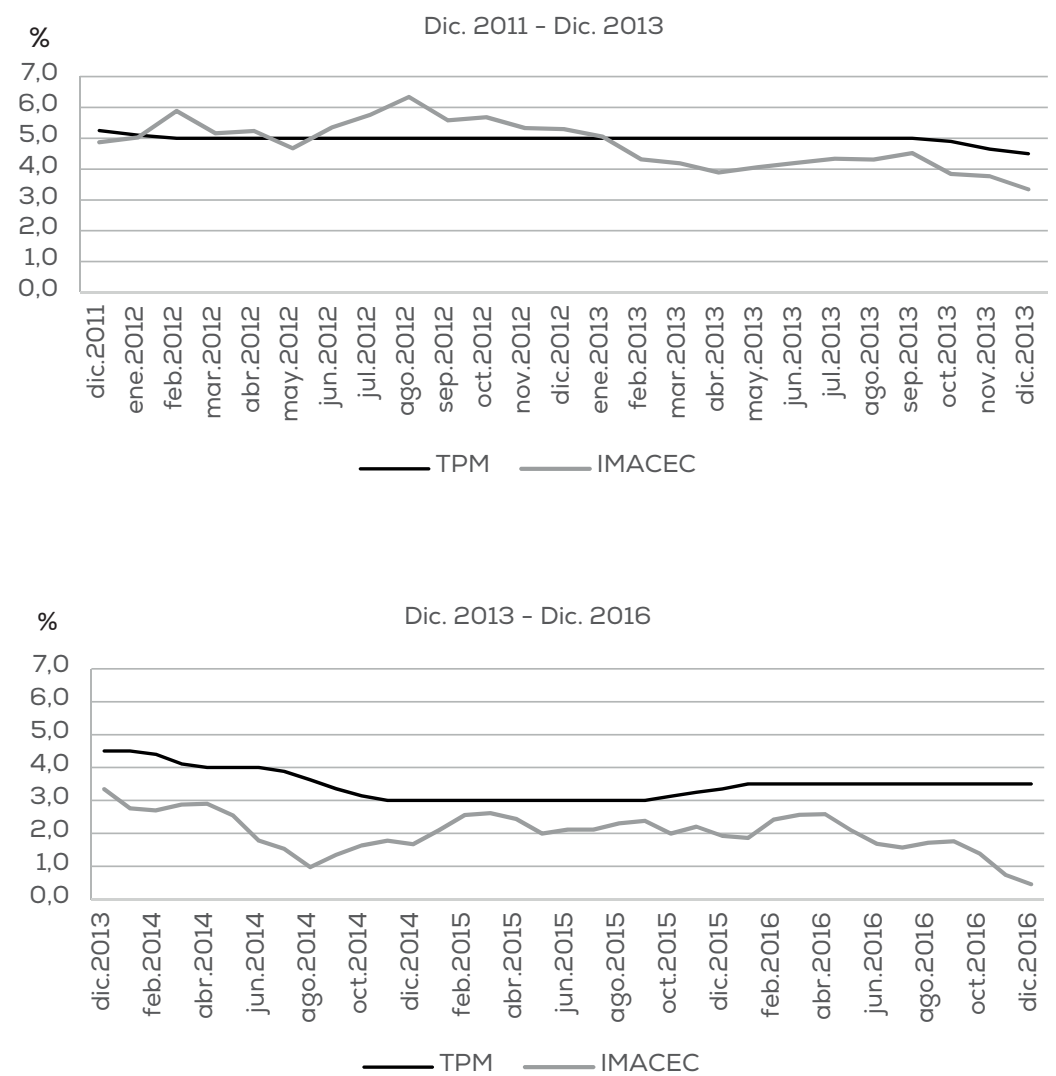

Fuente: Banco Central de Chile.

ello, salieron capitales del mundo emergente y se produjo una depreciación de muchas de sus monedas, entre ellas, y con más fuerza que otras, el peso chileno. En el gráfico 7 se muestra un índice del tipo de cambio nominal en varios países de América Latina. En el panel superior se ve lo que sucedió entre fines de 2011 y fines de 2013. Hasta mediados de 2013, con la excepción del real brasileño, todas estas monedas se apreciaron. A partir de entonces se observa una tendencia a la depreciación, con la excepción del peso mexicano que lo hizo más tarde. En el panel inferior se observa la misma evolución pero desde fines de 2013 en adelante. Se ve claramente que las monedas, incluido el peso chileno, se deprecian con fuerza en este período, pero que esta última se deprecia antes que el resto de las monedas y también se estabiliza antes. Pode- 
Gráfico 7. EVOLUCIÓN DE MONEDAS EN PAÍSES DE AMÉRICA LATINA

Dic. 2011 - Dic. 2013

(Moneda/USD, 2012=100)

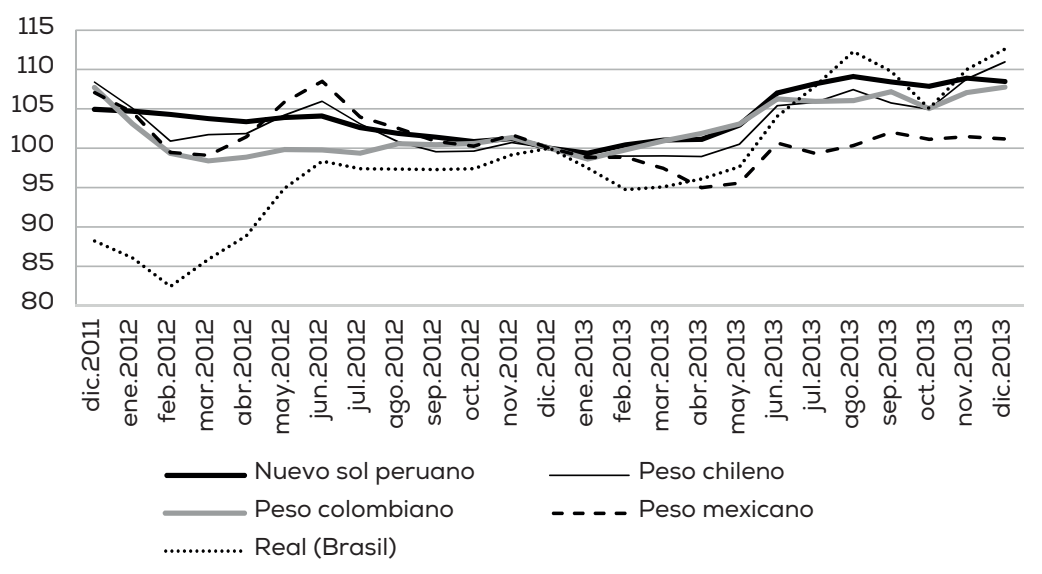

Dic. 2013 - Dic. 2016

(Moneda/USD, 2012=100)

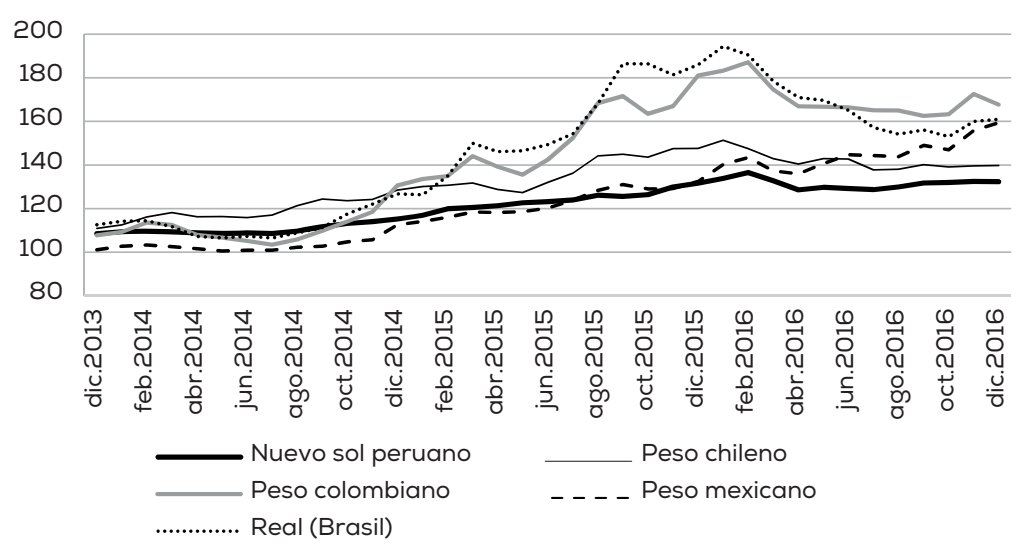

Fuente: Banco Central de Chile.

mos decir, entonces, que el ajuste cambiario en Chile fue más rápido que en otros países. Nótese que esto también contribuyó a que el déficit en cuenta corriente se ajustara más rápido que en otras partes. ${ }^{7}$

Entre abril y diciembre de 2013, el peso chileno se depreció 12 por ciento. Una de las consecuencias fue el alza en la inflación de

\footnotetext{
${ }^{7}$ Para 2014, el déficit ya había bajado a 1,7 por ciento del PIB.
} 


\section{Gráfico 8. CHILE: INFLACIÓN BIENES TRANSABLES Y NO TRANSABLES}

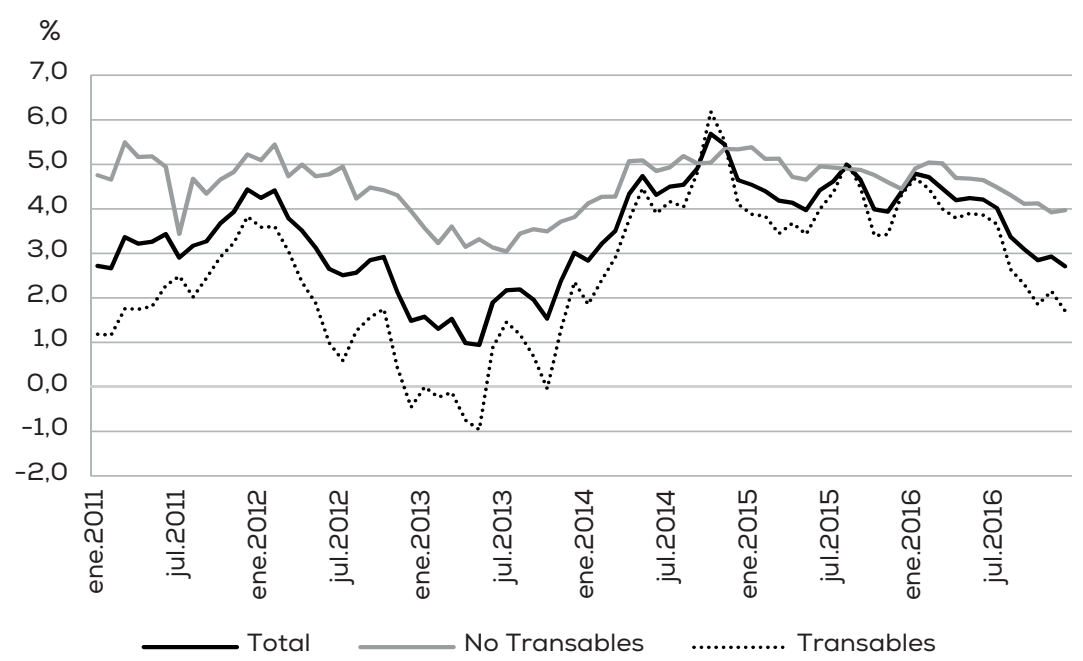

Fuente: Banco Central de Chile.

transables (pasa desde cifras negativas a fines de 2012 a sobre 2 por ciento a fines de 2013) y con ello la inflación total comenzó a subir gradualmente, para llegar a fines de año a 3 por ciento (gráfico 8). ${ }^{8}$ Por cierto, una de las consecuencias de esto fue que los reclamos por el bajo tipo de cambio cesaron rápidamente.

Pero junto con esto a mediados de 2013 comenzó a visualizarse otro fenómeno. El superciclo de las materias primas empezó a llegar a su fin, con diferente temporalidad en las distintas materias primas. El precio del cobre, después de llegar a un máximo en 2011, comenzó a caer. En 2012 bajó en 10 por ciento y en 2013, otro tanto. En los próximos años seguiría cayendo. Ello generó un efecto en la inversión minera y, con ello, en el total de la inversión. ${ }^{9}$

A mediados de 2013, el Banco Central visualizó que vendría una desaceleración de la economía y comenzó a dar señales respecto a que eventualmente implementaría una política monetaria más expansiva. En

${ }^{8}$ Para un análisis del efecto de la depreciación en la inflación, ver Albagli et al. (2015)

${ }^{9}$ Una de las mayores discusiones recientes ha sido respecto de cuánto de la caída de la inversión a partir de 2014 se debe a este fenómeno y a factores exógenos, y cuánto a factores internos, en particular relacionados con las reformas implementadas por la administración que asume en marzo de 2014. Ver Recuadro V.I. en el Informe de Politica Monetaria (IPoM), junio de 2015. 
julio introdujo un sesgo en su comunicado. En octubre bajó la TPM en 25 puntos base, lo que repitió en la reunión de noviembre, para llevar la TPM a 4,5 por ciento.

La inflación se mantenía por debajo de la meta, pero estaba subiendo y la depreciación hacía prever que podría seguir aumentando. Ello efectivamente ocurrió. Lo que no estaba previsto, no obstante, era que el tipo de cambio se seguiría depreciando con fuerza, lo que tendría un efecto adicional sobre la inflación. Con todo, este episodio marca el inicio de un período de mayor expansión monetaria en un escenario en que la inflación subía, pero la actividad se desaceleraba.

\subsection{Período 2014-2016: sube la inflación y baja el crecimiento}

A partir de 2014 empieza un período de bajo crecimiento en la economía chilena que se prolonga hasta hoy. La baja en la inversión minera, menores términos de intercambio y una economía mundial débil explican en parte este fenómeno. También hay elementos domésticos que no se pueden soslayar, que se tradujeron en una baja en la confianza tanto de consumidores como de empresarios, que cayó a niveles similares a los de la recesión de 2009. Ello fue sorprendente, dado que entre 2014 y 2016 la economía no entró en recesión y la tasa de desempleo se mantuvo relativamente baja. ${ }^{10} \mathrm{La}$ inversión fue el componente de la demanda que más se resintió. En la primera parte de este período, esto se explicó fundamentalmente por la menor inversión minera. Sin embrago, ya a partir de la segunda mitad de 2014 comenzó a cobrar relevancia lo que en un recuadro de un IPoM se denominó "shock autónomo", refiriéndose a aquella parte de la confianza que no podía ser explicada por un cambio en las condiciones macroeconómicas. ${ }^{11} \mathrm{El}$ concepto "shock autónomo" pasó entonces a ser parte de la discusión habitual cuando se debatía sobre la desaceleración y sus causas. Estrictamente hablando, éste sólo se refería a factores no habituales para explicar la caída de la confianza, sin hacer ninguna atribución específica. Dado que, a su vez, la confianza afecta la inversión, entonces se destacaba que se trataba de

${ }^{10}$ Aunque al final del período se empezaron a observar algunas señales de mayor debilidad del mercado laboral, como una mayor participación de trabajadores por cuenta propia, mayor cantidad de trabajos a tiempo parcial, etcétera. Ver Szederkenyi y Vergara (2017) para un análisis de la evolución cuantitativa de los trabajadores asalariados y los por cuenta propia.

${ }^{11}$ Informe de Política Monetaria, junio de 2015, Recuadro V.I. 
uno de los factores adicionales que estaban afectando la inversión. Muchos asociaron este shock autónomo al programa de reformas del Gobierno, aunque en dicho recuadro no había un análisis de determinantes posibles.

En materia de precios, se acentuó la volatilidad en los mercados externos y continuó la baja del precio del cobre, lo que llevó a depreciaciones adicionales del peso. En 2014, el peso se depreció en 16 por ciento en términos nominales y en 2015, otro 15 (gráfico 7). El efecto sobre la inflación de transables fue relativamente rápido (gráfico 8) y la inflación, con vaivenes, se aceleró. A fines de 2014, la inflación terminó en 4,6 por ciento y a fines de 2015 , en 4,4 , ambas cifras por sobre la meta. De hecho, la inflación había subido por arriba del 4 por ciento en abril de 2014 y se mantuvo en dichos valores (o cerca de ellos) ${ }^{12}$ hasta agosto de 2016 (gráfico 1). Esto es, la inflación estuvo sobre la meta por más de dos años.

¿Cuál fue la reacción de política monetaria? La respuesta fue clara: mantener la calma y hacer una política más expansiva a pesar de la mayor inflación. Durante 2014, la TPM se bajó en seis oportunidades, para llevarla a 3 por ciento. Quizás el caso más emblemático fue octubre de 2014, en que la inflación llegó a su máximo en este período (5,7 por ciento) y el Banco Central en el mismo mes bajó la TPM. ${ }^{13} \mathrm{La}$ razón para este accionar era que se trataba de shocks de oferta y, por lo tanto, con efectos por una sola vez en los precios. Así, la inflación estaría por sobre la meta por un tiempo, pero luego volvería a ella. La tasa de interés se bajaba porque en un escenario de menor crecimiento las brechas de capacidad se ampliaban y sostendrían una baja de la inflación a la meta a futuro. No tenía sentido hacer una política contractiva, aun con inflación elevada, porque se afectaría la demanda y la actividad más allá de lo razonable y necesario para llevar la inflación a su meta en el horizonte de dos años. Debe recordarse que, en promedio, entre 2014 y 2016 tanto la demanda como el PIB crecieron menos de 2 por ciento (gráfico 9). Nuevamente vemos en este episodio al cre-

${ }^{12}$ Hubo tres meses en ese período en que la inflación cayó a 4 por ciento y uno, a 3,9.

${ }^{13}$ Aunque, se debe reconocer, aún no se conocía la cifra de inflación en el momento cuando se realizó la reunión de política monetaria. En todo caso, la inflación en doce meses a septiembre, que sí se conocía, había sido de 4,9 por ciento. 
Gráfico 9. CHILE: PIB Y DEMANDA INTERNA

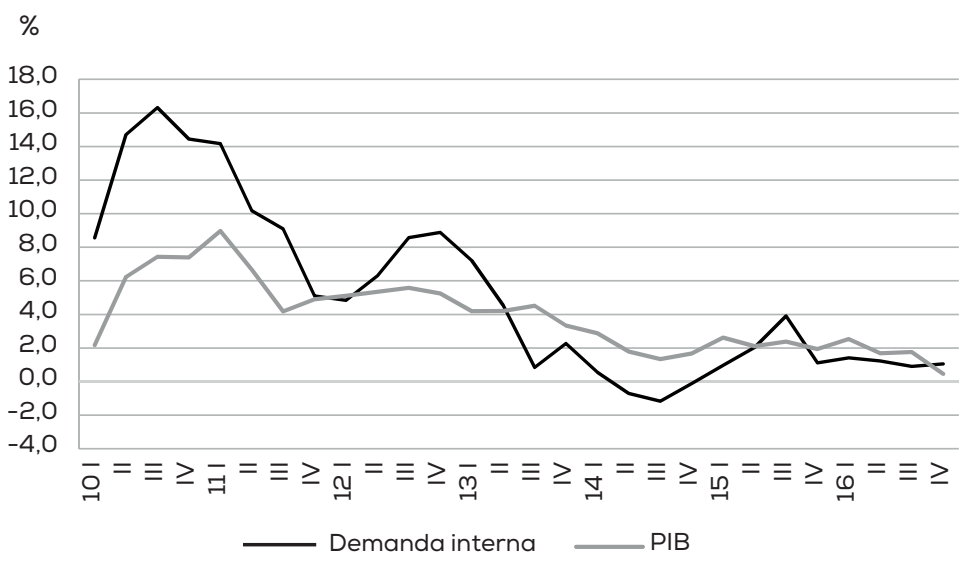

Fuente: Banco Central de Chile.

cimiento jugando un rol relevante y en el sentido opuesto del episodio del período previo.

Es importante destacar que en ese tiempo se pensó que la inflación volvería antes de lo previsto a la meta. Sorprendieron, sin embargo, las sucesivas depreciaciones. Como se mencionó, hubo depreciaciones importantes del peso en 2013, 2014 y 2015, además de una adicional a fines de 2015 y principios de 2016. Así, cuando se pensaba que la inflación cedía, venía una nueva depreciación y un nuevo efecto sobre la inflación, lo que hacía que ésta persistiera por más tiempo que el esperado por arriba de la meta.

Como es bien sabido en la literatura de metas de inflación, los shocks de oferta o de costos en general no debieran combatirse con una política monetaria más restrictiva con igual intensidad que los shocks de demanda. ${ }^{14}$ La situación, no obstante, se complica si se producen efectos de segunda vuelta, esto es, que la propia inflación retroalimente más inflación (Cuevas y Topak 2008). El problema de que se produzcan estos efectos de segunda vuelta es que ellos pueden tener una consecuencia negativa sobre las expectativas que, como vimos, son clave

${ }^{14}$ La razón es que, por lo general, los shocks de costos tienen un efecto negativo en el producto, lo que amplía la brecha (negativa) del producto, reduciendo las presiones inflacionarias. Ver, por ejemplo, Clarida et al. (1999). 
en este esquema. A fines de 2015 la situación se hizo algo más compleja, porque había antecedentes de que se empezaban a manifestar efectos de segunda vuelta. En ese contexto, se subió dos veces en 25 puntos base la TPM para llevarla de 3 a 3,5 por ciento, de forma de dejarle claro al mercado que el Banco Central haría lo que fuera necesario para mantener la convergencia de la inflación y, luego, las expectativas en la meta en el horizonte de proyección. Esa mera señal disipó cualquier duda o riesgo de efectos de segunda vuelta, suficiente desde el punto de vista del objetivo buscado.

Debe destacarse que algo similar ocurrió en otros países de la región, pero ellos requirieron alzas mucho más significativas de sus tasas de política (gráficos 10, 11 y 12). De nuevo, esto habla de la gran credibilidad con que cuenta el Banco Central de Chile, ya que tuvo la posibilidad de hacer un ajuste menor, mantener la política monetaria en un rango ampliamente expansivo y reducir al máximo la probabilidad de efectos de segunda vuelta. En el gráfico 13 se observa la TPM a fines de 2016 de los países de la Alianza del Pacífico más Brasil. Chile es el que entonces tenía la TPM más baja por bastante margen (y todavía es así). No sólo eso, las tasas de largo plazo también eran, por una diferencia significativa, las más bajas de la región (gráfico 14).

En síntesis, en este segundo período se siguió una política monetaria altamente expansiva en vista de la debilidad en la actividad, a pesar de que la inflación efectiva, debido a la depreciación del peso, superó la meta por un tiempo prolongado. Con el leve ajuste de 2015 se logró mantener las expectativas de inflación ancladas en 3 por ciento y acotar los efectos de segunda vuelta, que sí se vieron con fuerza en otros países de la región.

\subsection{Una breve discusión sobre el coeficiente de traspaso (pass through)}

Como se desprende de la discusión anterior, una variable clave en la inflación, al menos en el corto plazo, es la evolución del tipo de cambio. En el período en cuestión hubo inflaciones sobre la meta por un período prolongado, que tienen su explicación en las depreciaciones cambiarias que se observaron a partir de 2013. A pesar de ello, la literatura reciente sobre el coeficiente de traspaso (CT) muestra que éste ha 
Gráfico 10. TASA DE POLÍTICA MONETARIA (TPM) E INFLACIÓN (IPC) EN CHILE Y PERÚ
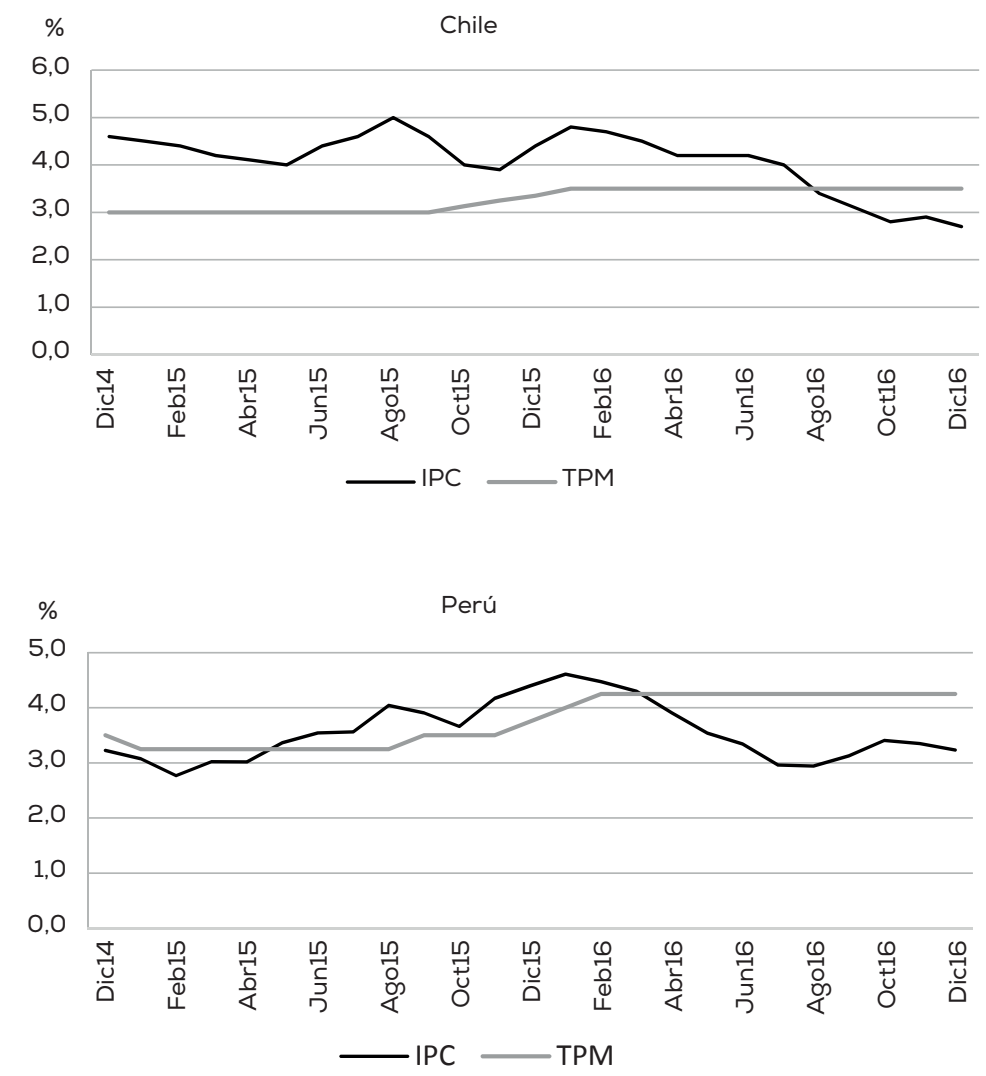

Fuente: Bancos Centrales de Chile y Perú.

disminuido en las últimas décadas. En otras palabras, un aumento en el tipo de cambio tiene un efecto sobre la inflación, pero este efecto es menor que el que se observaba hace años. Una de las explicaciones que se le han dado a este fenómeno es la credibilidad de los bancos centrales, particularmente de aquéllos autónomos con metas de inflación. De esta manera, si estas instituciones están dispuestas a hacer lo necesario para no tener desbordes inflacionarios, las expectativas inflacionarias y finalmente la inflación se contienen. Otros argumentos dicen relación con la globalización de las cadenas de producción, el cambio en la composición de las importaciones a sectores con menor coeficiente de traspaso (menos materias primas y más bienes manufacturados), la creciente 
Gráfico 11. TASA DE POLÍTICA MONETARIA (TPM) E INFLACIÓN (IPC) EN COLOMBIA Y MÉXICO
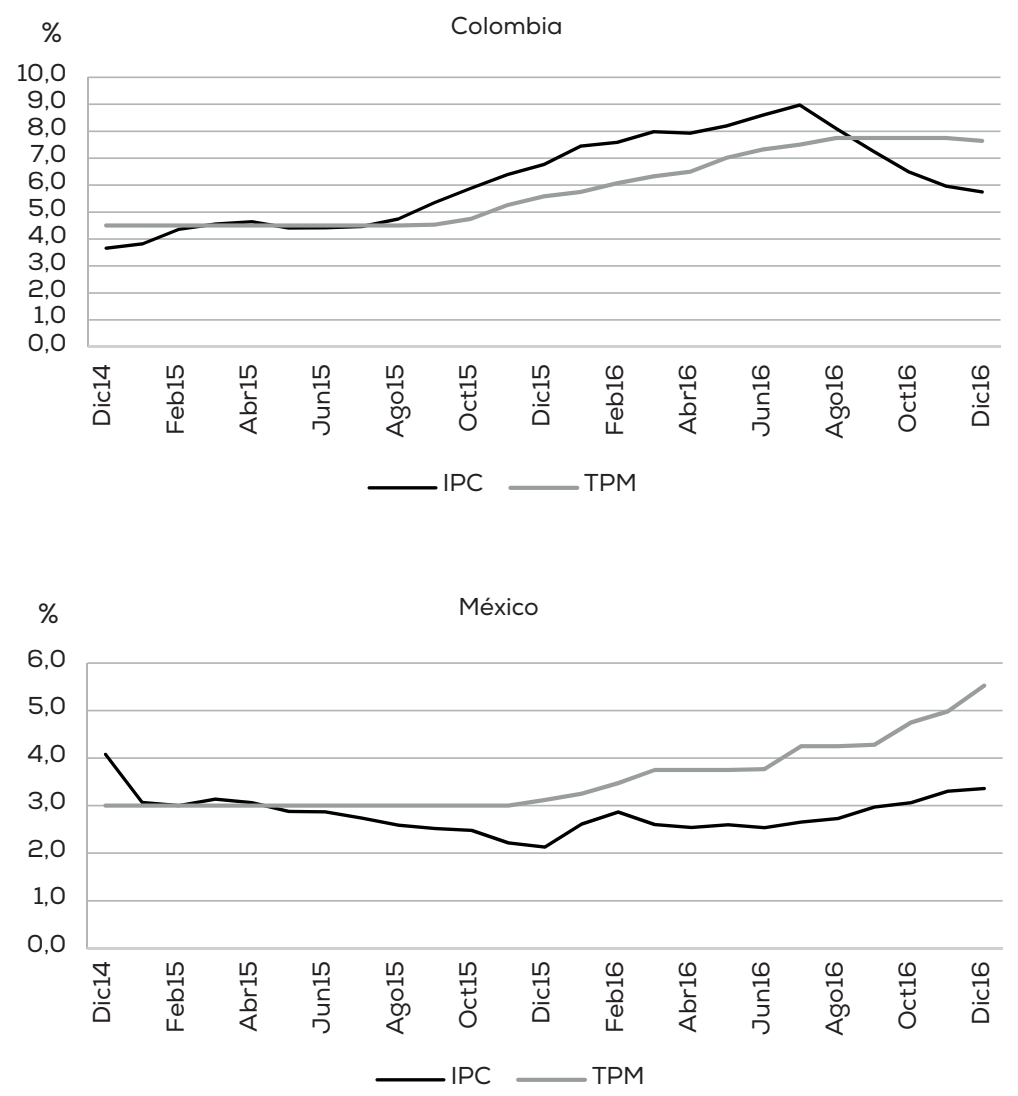

Fuente: Bancos Centrales de Colombia y México.

relevancia de los países emergentes, en particular China, en el comercio mundial, entre otros. ${ }^{15}$

¿Por qué, entonces, se usa como argumento la depreciación para explicar la inflación sobre la meta entre 2014 y 2016? Porque si bien el coeficiente de traspaso es menor, la depreciación fue lo suficientemente importante para afectar inflaciones que, además, hoy son más bajas. Estudios del Banco Central han estimado para Chile un coeficiente de traspaso del orden de $0,15^{16}$, lo que implica que una depreciación de 15

\footnotetext{
${ }^{15}$ Ver Campa y Goldberg (2005), Taylor (2000), Bailliu et al. (2010).

${ }^{16}$ Informe de Politica Monetaria, marzo de 2016, Recuadro IV.I.
} 
Gráfico 12. TASA DE POLÍTICA MONETARIA (TPM) E INFLACIÓN (IPC) EN BRASIL

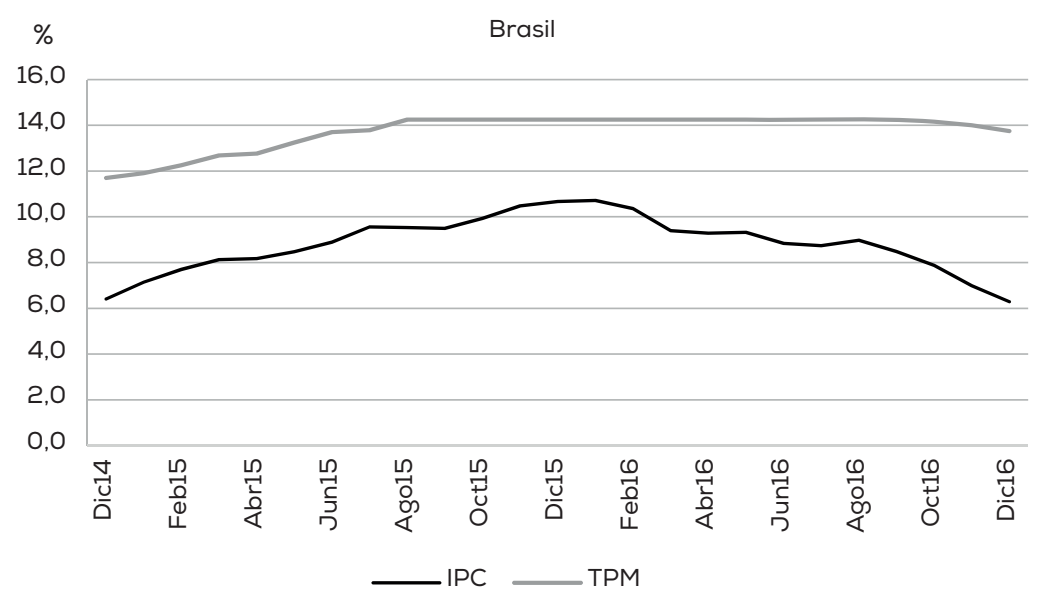

Fuente: Banco Central de Brasil.

Gráfico 13. TASA DE POLÍTICA MONETARIA A DICIEMBRE 2016

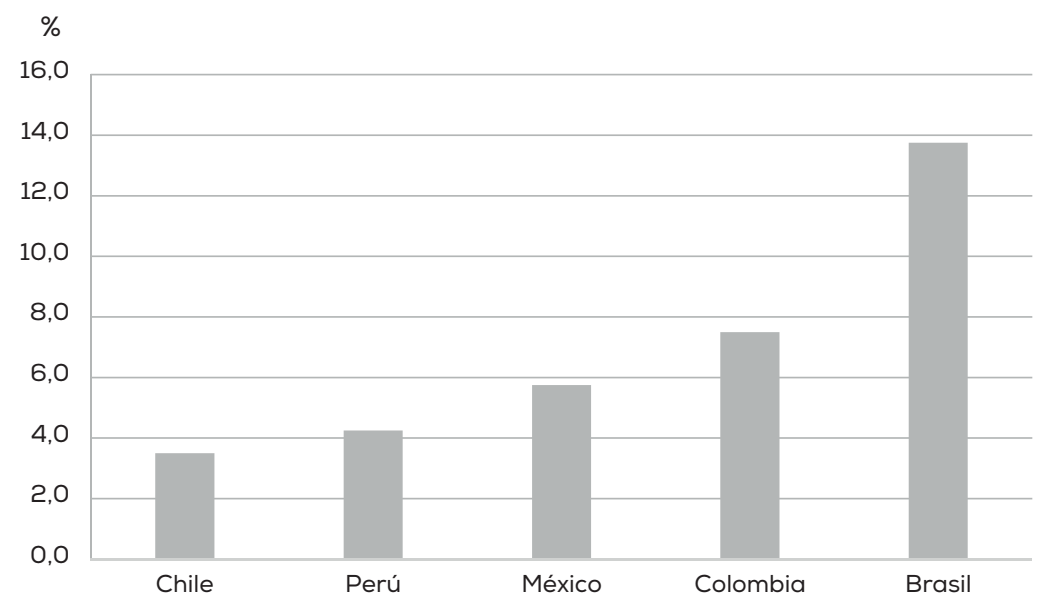

Fuente: Banco Central de cada pais.

por ciento, que es aproximadamente la que hubo en 2014 y 2015, tiene un efecto de 2,3 puntos porcentuales en la inflación. Ello es suficiente para sacar a la inflación del rango meta. Albagli et al. (2015) encuentran que el CT para un grupo de países de América Latina es en torno a 0,19 , muy superior al de economías avanzadas exportadoras de materias primas $(0,07)$, pero no tan distinto al de otros países emergentes exportadores de materias primas $(0,16)$. 


\section{Gráfico 14. TASAS DE BONOS DEL GOBIERNO A 10 AÑOS A DICIEMBRE 2016}

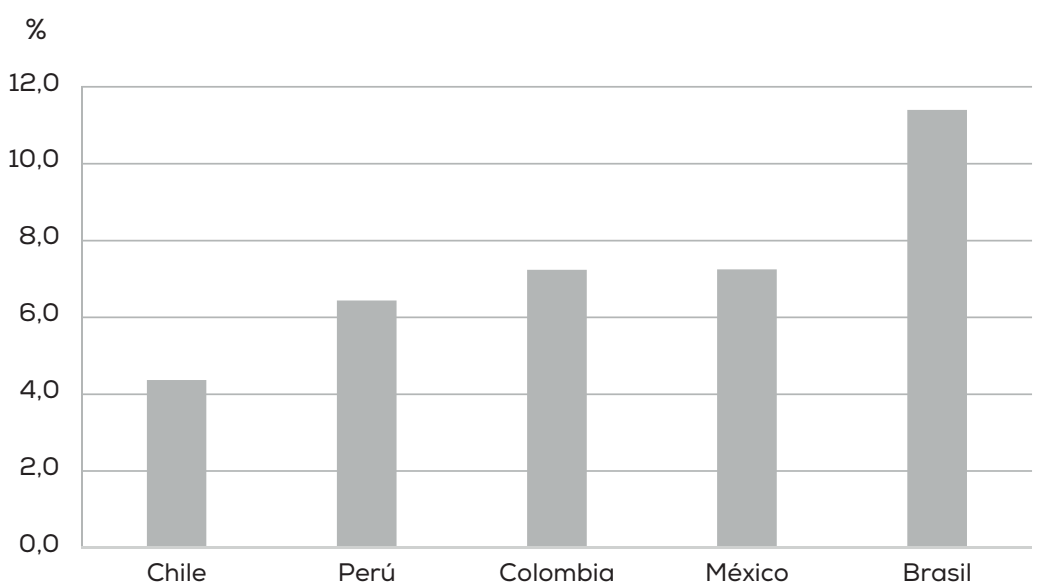

Fuentes: Bancos Centrales de Chile, Colombia y México; Ministerio de Economía y Finanzas de Perú; Bloomberg en el caso de Brasil.

En síntesis, aunque el CT es hoy menor que hace unas décadas, ${ }^{17}$ en Chile, como en otros países de América Latina, la depreciación fue lo suficientemente fuerte entre 2013 y 2015 (en algunos casos hasta 2016) para llevar a la inflación por arriba de los rangos metas. En el caso de Chile, el exceso sobre el rango meta fue muy inferior al de países como Colombia, Perú, México y Brasil.

\subsection{La brecha del producto}

Una de las variables clave en los modelos neokeynesianos para explicar la inflación es la brecha del producto; esto es, la diferencia entre el producto efectivo y el potencial. Una brecha positiva indica una sobreutilización de la capacidad instalada y, luego, mayores presiones sobre los precios. Sucede lo inverso cuando la brecha es negativa.

${ }^{17}$ Claro (2017), no obstante, ve una mayor correlación entre inflación y tipo de cambio en los últimos años en Chile, al compararse con la primera década de los 2000. Esto no es inconsistente con la literatura que indica un menor coeficiente de traspaso en el tiempo, ya que en general se refiere a la situación actual en comparación con las tres últimas décadas del siglo pasado. 
La brecha del producto entra en la denominada regla de Taylor (1993), que es una regla de política monetaria que liga la tasa de interés de política con la brecha y otras variables. ${ }^{18}$

De ahí que parte importante de la discusión de política monetaria tenga que ver con esta brecha. No obstante, el problema práctico con que se encuentran los bancos centrales es que la brecha del producto se calcula como la diferencia entre una variable observada (producto efectivo) y una variable no observada (producto potencial). ${ }^{19}$ La parte no observada se estima, pero, como cualquier estimación, está sujeta a errores. Por lo tanto, la brecha también está sujeta a errores. Por ejemplo, cuando en 2007 la inflación se aceleró y llegó al 7 por ciento, las estimaciones de la brecha en ese entonces arrojaban que ésta era cercana a cero. Sin embargo, cuando las estimaciones se rehicieron más adelante se llegó a la conclusión de que era bastante positiva, lo que de alguna manera permite explicar más fácilmente las elevadas inflaciones de esa época.

Dado este problema, los bancos centrales miran diversas variables que complementan la estimación de la brecha. Entre esas variables están el crecimiento, el gasto, el desempleo, el empleo, los salarios, entre otras. Estos indicadores permiten a la autoridad monetaria completar la visión que se tiene sobre presiones inflacionarias. Por ejemplo, cuando en 2013 se empieza a bajar la TPM fue porque se estimaba una brecha que se empezaba a cerrar y pasaba a ser negativa. ${ }^{20}$ Ello se complementaba con una desaceleración que la economía mostró a partir de la segunda parte del año y con indicadores que mostraban la pérdida de dinamismo del empleo.

Con todo, cabe señalar que nada de esto es matemático o exacto, por lo que siempre en estas decisiones está presente el juicio de los miembros del Consejo. Como dice el propio documento que explica los modelos que usa el Banco Central de Chile, ${ }^{21}$ por muy sofisticados que sean los modelos, ellos no sustituyen, más bien complementan, el juicio de los que están a cargo de la política.

${ }^{18}$ Entre otras, fundamentalmente con la diferencia entre la inflación efectiva y la meta.

${ }^{19}$ En estricto rigor, el cálculo del PIB también puede estar sujeto a errores, pero suponemos que ellos son menores en relación a los del PIB potencial.

${ }^{20}$ Nótese que tanto la brecha actual como las proyecciones de dicha brecha son importantes.

${ }^{21}$ Banco Central 2003. 


\section{ESTABILIDAD FINANCIERA22}

La crisis de 2008-2009 reveló una serie de debilidades del sistema financiero global, que estaban presentes en el marco regulatorio y de supervisión, en particular en las economías más desarrolladas del mundo.

Dichas debilidades ${ }^{23}$ se explican, posiblemente, por el rápido proceso de globalización y desarrollo de nuevos mercados y productos financieros durante las últimas décadas. Aunque ello tuvo muchos elementos positivos en términos de eficiencia de mercado, también es cierto que los sistemas de regulación y supervisión fueron ineficaces para monitorear o prevenir situaciones críticas de relevancia sistémica. Con el fin de reforzar la resiliencia de los mercados, la agenda regulatoria global se ha enfocado en enfrentar estas debilidades durante los últimos años. De esta manera, se ha realizado una revisión integral del funcionamiento de los sistemas financieros, así como del marco regulatorio y de supervisión en que operan. Formalmente, esto se ha llevado a cabo a través de iniciativas impulsadas por el foro G20, que buscan establecer una serie de estándares en diferentes áreas del mercado financiero, iniciativas que involucraron a los ministerios de Finanzas, bancos centrales y organismos de regulación y supervisión financiera de los mismos países, así como a organismos internacionales, como el Fondo Monetario Internacional (FMI), el Banco de Pagos Internacionales (BIS por su sigla en inglés) a través de sus comités, el Financial Stability Board (FSB) y la International Organization of Securities Commissions (IOSCO). ${ }^{24}$

Estas iniciativas se orientan especialmente a perfeccionar el funcionamiento global de los mercados, generando estándares comunes para las entidades que operan en ellos, apoyando de esta forma la estabilidad y el desarrollo de la economía. Además, después de la crisis se ha puesto un énfasis especial en acabar con el problema del "too big to fail", a través de una serie de recomendaciones y compromisos y de una mayor coordinación entre jurisdicciones. Todo esto apunta a minimizar el uso de dinero de los contribuyentes para salvar instituciones financieras.

Como consecuencia de estas iniciativas y de la propia experiencia generada por la crisis financiera internacional, varias jurisdicciones han

\footnotetext{
${ }^{22}$ Esta sección se basa fundamentalmente en Vergara (2016).

${ }^{23}$ Para más detalle ver Vergara (2015).

${ }^{24}$ G20 (2009), BCBS (2010 y 2011), FSB (2011) у CPMI-IOSCO (2012).
} 
implementado regulaciones nuevas y más estrictas, tanto en la banca como en la infraestructura del mercado financiero. Por ejemplo, en Estados Unidos se promulgó la ley Dodd-Frank, que trajo cambios sustanciales en la regulación financiera y donde destaca la "Volker rule", que prohíbe el trading por cuenta propia (es decir, transar en el mercado con posiciones de la propia institución y no de terceros), mientras que el capítulo VII.l impone una serie de restricciones a las transacciones con derivados. En Europa se creó la European Market Infrastructure Regulation (EMIR), con el objetivo de promover la estabilidad en los mercados de derivados en la Unión Europea, y que, entre otras cosas, considera un procedimiento para reconocer como equivalente el marco jurídico y de supervisión de países que no pertenecen a la UE.

El sistema financiero chileno no se vio afectado en lo fundamental por la crisis internacional del 2008-2009, más allá de algunos problemas puntuales de liquidez en moneda extranjera, para los que el Banco Central tomó las medidas necesarias. La simplicidad de nuestro sistema bancario, junto con una regulación y supervisión acuciosa, y una macroeconomía en orden, entre otros factores, explican por qué no fuimos afectados por los mismos problemas que enfrentó la banca en el mundo desarrollado. Sin embargo, dicha crisis nos llevó a repensar el tema de la estabilidad financiera y a tomar medidas para reducir la probabilidad de sufrir los efectos que tuvieron otras jurisdicciones.

Es así como el tema de la estabilidad financiera ha sido destacado por el Banco Central de Chile como uno de sus focos fundamentales en los últimos años. Debe recordarse que este banco tiene un objetivo explícito de preservar la estabilidad financiera a través del mandato, establecido en su Ley Orgánica Constitucional (LOC), de velar por la estabilidad del sistema de pagos internos y externos. Entre los aspectos que involucra esta regulación se incluyen las posiciones activas y pasivas de los bancos, la determinación del encaje bancario y reserva técnica, las características de los contratos de derivados de los bancos, normas de funcionamiento de las cámaras de compensación, regulación de los emisores y operadores de medios de pagos, conceder créditos de urgencia ${ }^{25}$, etcétera. ${ }^{26}$

${ }^{25}$ Esto último (créditos de urgencia) dice relación con el rol de prestamista en última instancia del Banco Central.

${ }^{26}$ Ver Raddatz (2015) para detalles. 
La mayor intensidad en este tema se ha reflejado de manera clara en el Informe de Estabilidad Financiera (IEF) y en cómo éste ha ido adquiriendo mayor relevancia. El IEF, que se publica semestralmente desde el año 2004, analiza el sistema financiero y advierte a los mercados de su situación, así como de los principales riesgos que han surgido desde el informe anterior. Dado el interés especial del instituto emisor en el sistema de pagos, el informe se enfoca naturalmente, pero no de manera exclusiva, en la banca. Como los bancos están al centro del sistema financiero, interactúan con muchos otros agentes financieros, tales como los fondos de pensiones y los fondos mutuos. Por tanto, también se monitorean y reportan los principales eventos y riesgos que enfrentan estos actores del mercado. A la vez, se analiza el comportamiento de ciertos precios claves, lo que incluye no sólo diversos márgenes de colocación y liquidez, sino también las acciones y, más recientemente, los precios inmobiliarios. Hay que tener en cuenta que el sistema financiero se hace cada vez más complejo, lo que ha implicado esfuerzos para estar al día en esta creciente complejidad, incorporando al análisis nuevos precios, segmentos y agentes del mercado. Se complementa el estudio de la oferta de servicios financieros con una encuesta financiera de hogares, que hace seguimiento a la posición financiera y el endeudamiento de las familias. ${ }^{27}$

La entrega de información al mercado sobre el estado del sistema financiero chileno y la percepción con respecto a la potencial formación de riesgos en algunos segmentos tiene un rol macroprudencial. A través de un estrecho intercambio con otros reguladores y supervisores, las advertencias del Banco Central pueden ser influyentes, a pesar de que en muchos aspectos éste no ejerce regulación directa sobre muchas instituciones financieras. Un ejemplo: en el IEF de diciembre de 2012 se manifestó preocupación por lo que estaba pasando con los precios inmobiliarios en Chile y se planteó al mercado, sin dejar lugar a dudas, que la tendencia observada no debía extrapolarse al futuro. Tras esta advertencia se ha visto cierto endurecimiento de las condiciones de préstamo en el mercado hipotecario, que se refleja en que una menor proporción de los créditos otorgados tiene un ratio LTV $^{28}$ superior al 80 por ciento. Más aún, compartían las aprensiones del Banco Central los supervisores

\footnotetext{
${ }^{27}$ Ver Vergara (2015b).

${ }^{28}$ Ratio entre la deuda o crédito y el valor del activo.
} 
del Consejo de Estabilidad Financiera. Así, a comienzos del 2014, la Superintendencia de Bancos e Instituciones Financieras (SBIF) emitió una nueva propuesta de regulación de las provisiones de créditos hipotecarios, en la que las asocia al ratio LTV del préstamo y al comportamiento de pagos, regulación que entró en vigor en enero del 2016.

En 2015, y luego de un proceso de análisis y consulta que duró dos años, el Banco Central implementó una nueva normativa de liquidez de la banca en conjunto con la SBIF, con el objetivo de incorporar los desarrollos y consensos internacionales sobre la regulación del riesgo de liquidez, en especial respecto de aquellos que surgen como consecuencia de las lecciones de la crisis financiera internacional y que están plasmados en las normas de liquidez de los Acuerdos de Basilea. Asimismo, durante estos años se dio un particular énfasis a las políticas macroprudenciales, las que, aunque han existido por años, han tomado un significativo impulso recientemente. ${ }^{29}$

No se puede dejar de lado en este recuento el enorme avance que el Banco Central ha hecho en materia de estadísticas financieras, tales como precios de viviendas, cuentas nacionales por sector institucional, tasas de interés por sectores, medidas de descalces cambiarios en el sector corporativo, estadísticas sobre el "shadow banking", participación en distintas iniciativas para el intercambio de información financiera entre el Banco Central y los otros reguladores y supervisores e información desagregada sobre derivados, entre otros.

En materia de sistema de pagos, ha habido numerosas iniciativas tendientes a perfeccionarlo, hacerlo más robusto y adaptarse a estándares internacionales cada vez más exigentes. ${ }^{30}$

A nivel más amplio, cabe destacar la instauración del mencionado Consejo de Estabilidad Financiera en 2011, inicialmente creado por decreto para luego pasar a ser ley en 2014. Dicho consejo, que incluye al Ministerio de Hacienda, a las superintendencias y al Banco Central, tiene por objetivo "facilitar la coordinación técnica y el intercambio de información entre sus participantes, en materias relativas a la prevención y al manejo de situaciones que puedan importar riesgos para el sistema (2016)

${ }^{29}$ Para más detalles y aplicaciones específicas en Chile, ver Raddatz y Vergara

30 Para una discusión ver Vergara (2015b). 
financiero, con el objeto de contribuir de este modo a cautelar la estabilidad financiera de la economía chilena".

Por último, es relevante mencionar que el Ejecutivo envió al Congreso un proyecto de ley de bancos que incluye la adopción de los estándares de Basilea III en materia de capital, cambios al gobierno corporativo de la SBIF y perfeccionamientos a los mecanismos de resolución bancarios.

\section{CONCLUSIONES}

El quinquenio que va entre 2012 y 2016 fue interesante y complejo para el Banco Central. Partió con un elevado crecimiento y baja inflación, para moverse, por las razones descritas, a mayor inflación y bajo crecimiento. La reacción de política monetaria fue la adecuada para los momentos que se vivían. Se bajó la TPM y se mantuvo una política monetaria expansiva a pesar de la mayor inflación, debido a que se trataba de un shock de oferta y era esperable que la inflación bajara en un contexto de menor dinamismo de la actividad. La inflación finalmente volvió a la meta en la segunda parte de 2016. Por cierto, ayudó el que la moneda no se siguió depreciando. De hecho, entre diciembre de 2015 y diciembre de 2016 el peso chileno tuvo una apreciación nominal de 5 por ciento. Lo que sucedió con la inflación dio la razón al Banco Central, en cuanto a que era importante permitir la depreciación del peso aun sabiendo que la consecuencia era una mayor inflación transitoria. No fue fácil porque hubo muchas críticas en la medida en que la inflación se mantuvo por sobre la meta por más tiempo que el previsto. Pero haber pretendido defender el tipo de cambio con mayores tasas de interés no sólo no hubiera sido óptimo desde el punto de vista de la política, ya que el nuevo escenario requería de un tipo de cambio real más elevado, sino que también hubiera tenido costos indeseados sobre la actividad y, por lo demás, no hay ninguna seguridad respecto a que hubiera sido efectivo.

Estimo que si el esquema de política es correcto y claro, y si además existe credibilidad, se termina logrando el objetivo inflacionario. Recuérdese que el esquema es flexible, por lo que existe espacio para ir adaptándose a las circunstancias que plantea el escenario económico, lo que, por cierto, ayuda, pero es un factor que hay que saber administrar. 
Finalmente, todo el periodo estuvo marcado por los fuertes cambios internacionales en materia de regulación financiera. Aunque en Chile no hubo crisis financiera, sí se aprendió de las experiencias de otras latitudes. La regulación se ha ido adaptando gradualmente para cumplir con las nuevas normas internacionales.

\section{REFERENCIAS}

Albagli. E., A. Naudón \& R. Vergara. 2015. "Inflation Dynamics in Latin America: A Comparison with Global Trends and Implications for Monetary Policy". Documentos de Política Económica 58. Banco Central de Chile.

Bailliu, J., W. Dong \& J. Murray. 2010. "Has Exchange Rate Pass-Through Really Declined? Some recent Insights From the Literature". Bank of Canada Review (Autumn): 1-8.

Banco Central de Chile. 2003. "Modelos Macroeconómicos y Proyecciones del Banco Central de Chile".

_. 2007. "La política monetaria del Banco Central de Chile en el marco de metas de inflación".

—. 2015. "Expectativas e inversión". Recuadro V.I. del Informe de Política Monetaria, junio de 2015: 35-37.

—. 2016. "Traspasos del Tipo de Cambio a Precios". Recuadro IV.I. del Informe de Política Monetaria, marzo de 2016 33-34.

Barro, R. \& D. Gordon. 1983. "Rules, Discretion and Reputation in a Model of Monetary Policy”. Journal of Monetary Economics 12 (julio): 101-121.

BCBS. 2010. "Basilea III: Marco internacional para la medición, normalización y seguimiento del riesgo de liquidez". Diciembre.

— 2011. "Basilea III: Marco regulador global para reforzar los bancos y sistemas bancarios - Rev. junio de 2011". Junio.

Bernanke, B. 2013. "The Economic Outlook". Testimonio ante el Joint Economic Committee, Congreso de EE.UU., 22 de mayo, Board of Governors of the Federal Reserve System. https://www.federalreserve.gov/newsevents/ testimony/ Bernanke 20130522a.htm/.

Campa. J. \& L. Goldberg. 2005. "Echange Rate Pass-Through into Import Prices". Review of Economics and Statistics 87 (4): 679-690.

Clarida R., J. Galí \& M. Gertler. 1999. "The Science of Monetary Policy: A New Keynesian Perspective". Journal of Economic Literature Vol. XXXVII (diciembre): 1661-1707.

Claro, Sebastián. 2017. "Crecimiento, tipo de cambio y la política monetaria en Chile". Presentación en seminario Fruittrade 2017, Santiago. Banco Central de Chile.

CPMI-IOSCO. 2012. "Principles for Financial Market Infrastructures". Abril. 
Cuevas, A. \& S. Topak. 2008. "Monetary Policy and Relative Price Socks in South Africa and Other Inflation Targeters". IMF Working Paper 08 / 289.

FSB. 2011. "Key Attributes of Effective Resolution Regimes for Financial Institutions". Octubre.

G20. 2009. "Leaders' Statement: The Pittsburgh Summit". Septiembre.

Raddatz, C. (2015). "La Economía ante las crisis financieras. ¿Cómo evitar que ocurran?", discurso preparado para un panel del mismo nombre realizado en el contexto del Primer Seminario Finanzas y Ética: Finanzas y crisis económicas: experiencias y lecciones para Latinoamérica, organizado por la Universidad Alberto Hurtado, Santiago, Chile, 21 de octubre.

Raddatz, C. \& R. Vergara. 2016. "Macroprudential Policies: General Analysis and a Look into the Chilean Experience". Documento de Política Económica 59. Banco Central de Chile.

Svensson, L. 1997. "Inflation Forecast Targeting: Implementing and Monitoring Inflation Targets". European Economic Review 41 (6): 1.111-1.146.

- 2009. "Flexible Inflation Targeting: Lessons from the Financial Crisis". Discurso dado en el seminario Towards a New Framework for Monetary Policy? Lessons From the Crisis. Banco Central de Holanda, Amsterdam.

Szederkenyi, F. \& R. Vergara. 2017. "Evolución del Empleo en Chile: Asalariados y Cuenta Propia”. Puntos de Referencia 457. Centro de Estudios Públicos.

Taylor, J. 1993. "Discretion versus Policy Rules in Practice". Carnegie-Rochester Conference Series on Public Policy 39: 195-214.

Taylor, J. 2000. "Low Inflation, Pass-Through, and the Pricing Power of Firms". European Economic Review 44 (7): 1389-1408.

Vergara, R. 2015a. "Chile y la agenda regulatoria financiera global". Documento de Política Económica 57. Banco Central de Chile.

- 2015b. "Perfeccionando la estabilidad financiera mediante políticas macroprudenciales: Implicancias sobre la política monetaria”. Discurso efectuado con motivo de la XCIX Reunión de Gobernadores de Bancos Centrales del Centro de Estudios Monetarios Latinoamericanos. 28, 29 y 30 de mayo, Cancún, México.

- 2016. "Política monetaria en tiempos complejos". En 25 Años de Autonomía del Banco Central de Chile, editado por Alberto Naudón y Luis Álvarez, 101-130. Santiago: Banco Central de Chile. EP 
